\title{
FANTASMAS DE LO ESCOLAR. ¿A QUIÉN VAS A LLAMAR?
}

\section{Ghosts of school. Who you gonna call?}

\author{
Mariano NARODOWSKI \\ Universidad Torcuato Di Tella, Argentina \\ mnarodowski@utdt.edu \\ https://orcid.org/0000-0002-3122-052X
}

Fecha de recepción:22/11/2020

Fecha de aceptación: 15/02/2021

Fecha de publicación en línea: 01/07/2021

Cómo citar este artículo: Narodowski, M. (2021). Fantasmas de lo escolar. ¿A quién vas a llamar? Teoría de la Educación. Revista Interuniversitaria, 33(2), 49-63. https://doi. org/10.14201/teri.25136

\section{RESUMEN}

El artículo propone una serie de conceptos teóricos que permiten comprender el pasado y el futuro de las instituciones escolares a partir de una recuperación de la subsistencia de las ideas de J. A. Comenius en el campo de lo escolar, proyectando las líneas más importantes que desembocan en la crisis actual, utilizando un enfoque que combina estudios previos de autores posestructuralistas y aceleracionistas.

En la primera parte, se presenta un diagnóstico que muestra cómo la vieja tecnología escolar resiste la aceleración de las nuevas tecnologías de trasmisión y apropiación de saberes (digital e inteligencia artificial) generando un efecto de nostalgia que tiende a paralizarla y a obturar toda posibilidad de conciliarla con proyectas futuros. A la vez, el estudio pone de manifiesto la nociva recurrencia por parte de la pedagogía a la recuperación de mandatos y consignas que se muestran impotentes frente al desacople tecnológico entre los dispositivos escolares surgidos en el siglo XVII y los que operan en el siglo XXI. 
En la segunda parte, el estudio encuentra lo productivo que puede llegar a ser un ejercicio fantasmagórico que propicie una negociación entre lo viejo y lo nuevo, con la condición de no resignar el ideal pansófico comeniano (todo el saber humano para todos los seres humanos) que originalmente dio sentido a lo escolar como medio para alcanzar ese fin, sino más bien liberándolo de la sujeción a un único formato educativo y, por tanto, proponiendo un horizonte progresista y realizable frente a la crisis actual.

Palabras clave: tecnología escolar; tecnología digital; aceleracionismo; Pansofía; Comenius.

\section{ABSTRACT}

This article proposes a series of theoretical concepts that allow a better understanding of the past and future of schools by way of J. A. Comenius' ideas regarding the subject matter, and by projecting its most important points that lead to the crisis that is currently underway. Furthermore, the article uses an approach that combines the works of previous poststructuralist and accelerationist authors.

First, the article presents a diagnosis that illustrates how the old school technology resists as such in the face of the acceleration of new technologies of knowledge transmission and appropriation (be them digital or of artificial intelligence). This creates a nostalgia that tends to paralyze the school and to hinder any possibilities of it being reconciled with future projects. Moreover, the study shows how pedagogy harmfully insists on mandates and slogans that prove to be impotent in the face of the disengagement between the school technology that arose in the 17th century and those which operate in the 21st century.

Secondly, the study finds how productive a phantasmagoric approach can be, whereby it encourages a negotiation between the old and the new under the strict condition that the Commenian pansophic ideal (all human knowledge for all human beings) that originally saw the school as a means to that end, is not resigned, but rather freed from that format as the only viable one and, therefore, proposing a progressive and achievable horizon in the face on the current crisis.

Key words: school technology; digital technology; accelerationism; pansophy; Comenius.

Ella asintió, preguntándose por qué podía absorber sus palabras con tanta facilidad.

Quizá porque, ya antes de su captura, había sabido que el mundo que ella había conocido estaba muerto. Y ya había absorbido esta pérdida en el grado que le era posible.

(O. Butler, 1989, p. 28) 


\section{Fantasmas}

Hasta ahora, nos hemos aferrado a las escuelas como objetos naturales e inherentes por sí mismos. Como objetos eternamente activos que están sin otra dimensión que su propia multiplicación en el pasado y en el futuro. O, mejor, hemos adjudicado a los sistemas escolares una visión eternizada que no fue atravesada por una mirada de la complejidad y la autopoiesis y sin advertir propiedades asintóticas que la pongan en riesgo.

Ya en el siglo XVII, en el capítulo XI de la versión latina de la Didáctica Magna, Comenius (1984, p. 82) advertía que "Hasta ahora carecemos de escuelas que respondan perfectamente a su fin» lo que, como en muchos otros pasajes de esta obra y de otras, el gran pedagogo bohemio le da al pensamiento pedagógico de la modernidad dos características funcionales: por un lado, la presencia de esta crítica a las escuelas aun cuando ella estaba siendo fundada en este discurso. La segunda, la identificación de esta falla constitutiva para extraer de ella la inferencia de lo que «una verdadera escuela» debe ser; aunque este deber ser sea siempre concebido como una búsqueda utópica que consagra la presencia irrenunciable, desde sus orígenes, de la disconformidad sobre lo escolar, una suerte de melancolía auto conservada, una neurosis constitutiva de nuestro pensamiento pedagógico moderno.

Pero esa naturalización ya no es eficaz, a pesar de que la sostenemos contra todo pronóstico y contra toda intuición. Como lo advirtió Baudrillard (1977) en su burla a los vítores de los foucaultianos por creer haber encontrado la llave interpretativa del disciplinamiento social, los poderes son eficaces, lamentablemente, solo hasta el momento que los descubrimos, hasta que se nos hacen presentes, hasta que corroboramos con nuestros propios ojos la patética desnudez del rey: una vez que se extingue el sonido de la última campanada de palacio, solo quedan los fantasmas rondando y el objeto deseado se nos aparece con sus dos caras opuestas: la del ángel purificador al que nunca deberíamos renunciar y la del monstruo temible que, en el mejor de los casos, podrá ser domesticado por expertos conocedores de los laberintos de sus secretos, por especialistas en exorcizar sus costados siniestros.

Y las últimas campanadas de la fiesta de gala en el palacio escolar sonaron hace rato. La décima campanada se oyó en los años sesenta, cuando el estructuralismo descubrió que las escuelas no zafaban de las reglas generales de la sociedad capitalista por lo que no solamente eran insuficientes para los postulados igualitarios que pregonaban, sino que, en términos de su dinámica, contribuían a la reproducción del capital; muy lejos de, como se presumía, crear las condiciones para su superación. Y, concluían, la trasmisión de conocimiento escolar difícilmente podría llegar a burlar a la trasmisión intergeneracional tanto de privilegios económicos y culturales como de la pobreza. Algunos exégetas tardíos de este estructuralismo han encontrado en estas invariantes orgánicas la posibilidad de lucha y resistencia y han construido identidades que permiten asimilar el golpe con esperanza y decisión: 
el aturdimiento del campanazo también provoca estos devaneos nostálgicos que habremos de analizar luego.

La campanada número once reverberó de la forma menos pensada: la globalización. Las escuelas son efecto de un proceso de mundialización de la educación que se inició en los albores del siglo XIX y que todavía está sucediendo. Que la foto de una escuela en el centro del Acre amazónico muestre inquietantes similitudes con una escuela del centro de Helsinki, de la villa de Ornen, de Ereván o con cualquiera de un barrio pobre de Seúl hoy ya a nadie sorprende. Y cuando nos atrevimos a seguir el rastro de sus respectivas conformaciones mostramos cómo la escuela (la tecnología escolar) se reprodujo a escala mundial con sus salas de clase, sus gobiernos estatales y sistémicos, sus contenidos unificados territorialmente y sus asimetrías adulto-niño, entre otros dispositivos (Narodowski, 1994). De aquella difusión mundial estas materialidades comunes: las escuelas son (cada vez más) iguales a sí mismas

Pero la globalización de las comunicaciones y los consensos internacionales hegemonizados menos por organismos educacionales ad hoc como la Liga Internacional de la Escuela Nueva o la UNESCO y más por organismos del comercio, las finanzas y el mercado mundial como el Banco Mundial o la OCDE, han tendido a estandarizar aquello que la tecnología escolar dejaba en manos de gobiernos, editoriales de textos escolares, pedagogos locales y docentes: complejas evaluaciones internacionales y nacionales producen, en forma estandarizada, datos sobre el comportamiento cognitivo de centenas de millones de alumnos y docentes de miles de escuelas del mundo. Estos datos son procesados, analizados y empaquetados de acuerdo a formatos diferentes: archivos de texto para consumo mediático, PDFs con imágenes e infografías hipersimplificadas para escuelas como «retroalimentación para la mejora", Excels más sofisticados para algunos analistas y PASW o SPAD-N para expertos que puedan operar en el acondicionamiento y consolidación de grandes bases de datos y en el procesamiento estadístico de información para la realización de análisis factorial de componentes principales y análisis de conglomerados o clústeres.

El dato se convirtió en la celebrity del show global de la educación con su héroe inesperado — Finlandia- quien permitió a los cultores del viejo orden mostrar, por la vía de la paradoja; es decir, por medio de las evaluaciones estandarizadas. la inutilidad de implementar evaluaciones estandarizadas. Pero también China, Singapur y Vietnam, países que no pasan un mínimo examen de democracia y estado de derecho, se convierten en adalides mundiales gracias a la combinación de datos. Parafraseando el dicho popular: más vale una base nominal de estudiantes perfectamente diagramada y prolijamente ordenada que produzca datos en tiempo real respecto de lo que aprenden en sus escuelas en mano, que cien textos pedagógicos hablando de la libertad y la democracia volando. 
Así, a la delicada y artesanal construcción individual o colectiva de maestros de escuela que se afanaban por generar una solución a los problemas escolares, se le opone una pregunta brutal, descarnada: ¿Cuál es la evidencia? Si la respuesta no contiene paquetes de datos depurados y si su propuesta no es escalable; traducida del nivel micro escolar de la experiencia pedagógica al hecho estilizado, por medio un puñado de supuestos inconfesablemente neoclásicos respaldados en... datos, difícil es que sea aceptable por este nuevo consenso global. A no ser que se la admita por medio de mueca empática y compasiva que con su mohín de ocultado desprecio señala cuán rudimentarias eran las cosas antes de que suene esta anteúltima campanada

Esta fascinación por el dato que evidencia el fin del festín no es exclusiva de lo escolar y las redes sociales lo atestiguan con cada like, con cada view, con la visibilidad del número de seguidores. Sin embargo, el impacto sobre lo escolar es perturbador: la vieja autoridad del docente va a quedar diluida en una parafernalia cuantificada en la que pasa de ser el centro de la legitimidad a conformar un eslabón más (un link) en la función de producción.

El significado de la última y postrera campanada, la de la medianoche fatal, es tan conocido y sus efectos han sido tan zarandeados que cuesta agregar algo nuevo, aun cuando las consecuencias de su reverberar tengan una longitud de onda tal que los oídos pedagógicos más sensibles no puedan quitarse ese sonido de la cabeza ni con los esfuerzos terapéuticos más denodados. Aun cuando el efecto cuasi hipnótico del campanazo final sobre una pléyade de educadores dispuestos a sacrificarse por los designios del suave susurro de su palpitar no solo que no han cesado, sino que se reproducen (el susurro campanero y la consecuente hipnosis) y alteran esos silencios cansinos que la pedagogía hubo de callar en los últimos siglos.

Se trata, qué duda cabe, de la llamada tecnología educativa o tecnología digital aplicada a los procesos educacionales. Un entremezclado variopinto de inventos añejos que van desde la radiofonía a la cinematografía, de la televisión al vídeo, de la vieja máquina de enseñar de Skinner a las computadoras personales, de las clase de informática y las salas de computación de las escuelas a dispositivos que desde Negroponte operan en red, tan pequeños y ubicuos que pasan desapercibidos en los bolsillos o las mochilas de los alumnos, a punto tal que en no pocos sistemas escolares tuvieron la sempiterna idea de prohibirlos: idea imperecedera de las viejas locaciones territoriales de las escuelas aunque de efectos risibles después de la campanada.

Tal es la fuerza del embate tecnológico que hasta ha capturado al propio significante. Sabemos que la escuela es una tecnología; una muy poderosa capaz de organizar grandes cantidades de saberes y articularlos con grandes conglomerados humanos, particularmente en las primeras etapas de su vida, de una manera sofisticada en cuanto a tiempos, espacios, jerarquías, grados y órdenes. Y capaz de capturar en un espacio de encierro con tiempos claramente delimitados a una 
población infantilizada a la que se les es prohibido el trabajo que junto a sus progenitores habían desarrollado durante milenios. Una tecnología nombrada como de guarda o cuidado por algunos o de secuestro por otros pero que, se llame como se llame, permite el control biopolítico sobre la infancia y la regulación, al menos la pretensión de regulación, de los flujos poblacionales y de ingreso a los mercados de producción y consumo, además de un entrenamiento en prácticas endogámicas de cohesión social.

Una tecnología que, además, fue la más poderosa de la historia para distribuir conocimiento humano llegando incluso a ilusionarnos a muchos con el cierre de la brecha que la tecnología escriturada abrió hace siete mil años con relación a la tecnología oral, aquella que viene en el equipo biológico juntamente con la capacidad de abstracción como efecto de procesos neurobiológicos neo corticales. En efecto, la modernidad pretendió reunificar la genericidad específicamente humana quebrada por el registro escriturado, que relegaba del conocimiento a aquellos a quienes no les había sido dada la alfabetización. Merced a la tecnología escolar ya no habría excusas para la ignorancia y la ilustración general estaba al alcance de la mano de una burguesía que todavía se percibía a sí misma como revolucionaria $\mathrm{y}$, de hecho, consiguió inocultables avances en el acceso al saber para buena parte de la humanidad.

Pero esta tecnología no es, a nuestro pesar, LA tecnología. La vieja tecnología es la escuela a secas, la nueva tecnología es la tecnología digital. Y esta batalla terminológica (perdida antes de empezar, por cierto) no hace más que reflejar una capitulación mucho más importante: hace tiempo ya que la tecnología escolar resignó su carácter monopólico en los procesos de distribución de saber, no solo porque lo digital ha colonizado nuevos espacios antes vírgenes y ha expandido el acotado y amarrete continuum físico plegando y desplegando espacios virtuales infinitos, sino porque la tecnología escolar, y con ella especialmente los maestros, van perdiendo legitimidad respecto de sus atributos de origen y no les queda más que virar a la construcción de legitimidad en el ejercicio cotidiano, lo cual supone que algunas batallas se pueden ganar pero otras, muchas otras, se pueden perder. Y se pierden.

Y estas nuevas tecnologías parecen lastimar nuestra humanidad, nuestra genericidad unificada, nuestro proyecto moderno de igualdad. No es nuevo en la historia porque anarquistas y luditas ya destruido máquinas de vapor que, en el proceso de urbanización e industrialización, destruían las viejas formas de relación humana (expresada como relación laboral) y alienaban a capitalistas y trabajadores a un sector del otro y a ambos, y al mismo tiempo, del género humano.

La pedagogía observa con triste resignación cómo se deshumaniza el cuadro humanizado que la escuela había intentado y, por qué no, logrado recomponer después del hiato de alienación fatal creado a partir del surgimiento de la escritura. ¿Y cómo sucedió? Esta irrupción de pantallas, redes e inteligencia artificial supone 
dos elementos propios que subvierten radicalmente la apacible armonía de la tecnología escolar. El primero, es la noción misma de futuro; el segundo es la aceleración.

Jean-Baptiste Say, en las primigenias épocas de turbulencia política y confusión del capitalismo, decía que en esos momentos todo se aceleraba porque la gente se ve incitada a consumir la totalidad de sus ingresos. Su Traité d'Économie Politique (1861) fue publicado en el vórtice de esas turbulencias y confusiones del capitalismo británico y francés, aquel que Marx llamara pocos años después, la etapa arrolladora o descarnada del capital, cuando la tecnología industrial avanzaba sin reparos sobre quienes debían operar las máquinas y al final terminaban operados por ellas, en un ensamble ya evidente entre el afuera y el adentro.

Pues bien, la breve historia de la tecnología escolar muestra que su desarrollo se ajusta mucho más a un capitalismo no descarnado porque épocas menos voluptuosos y rapaces permiten épocas de la espera propias de lo escolar. En efecto, las escuelas precisan de ritmos serenos que conforman gradualidades que atraviesan meses, años y décadas para cerrar trayectorias previstas de antemano. Trayectorias expectantes que se realizan a través de larguísimos años, desde los 3 o 4 de edad hasta los 18 y mucho más. Tiempos sujetos a espacios estáticos en los que se prevé de antemano, por medio de documentos avalados por un nihil obstat estatal aquello que debe suceder, y cuya modificación requiere otros tanto largos años de deliberación.

De hecho, los estudios historiográficos de Querrien (2005) han demostrado que la tecnología escolar triunfante en la primer mitad del siglo XIX — y sobreviviente hasta la actualidad - era mucho menos efectiva en términos de organización y moral capitalista que los intentos de Joseph Lancaster y Jeremy Bentham por introducir una práctica educacional utilitarista que abreviaba enormemente los tiempos de escolaridad y supeditaba la gradualidad al desempeño individual y no a la organización anual de las escuelas, como finalmente terminó sucediendo. Podríamos con la autora balbucear algunas respuestas a la pregunta de por qué no triunfó el método lancasteriano siendo que su organización manifestaba una correspondencia evidente con la organización fabril. Nos vemos tentados a inferir que la organización lancasteriana era hija de la etapa capitalista descarnada mientras que con la afirmación del capitalismo y de Estados con capacidad de captar ingresos y redistribuirlos en sectores empobrecidos, los tiempos pudieron alargarse: la segunda mitad del siglo XX fue el siglo de la escuela, el que hizo crecer todas las esperanzas de que el ideal pansófico proclamado por Comenius - el saber humano es para todos los seres humanos- pudiese alguna vez concretarse.

El drama de lo escolar es el derrumbe paulatino pero constante de las certezas totalizantes propias de un nuevo capitalismo des-descarnado. La crisis fiscal del Estado en los setentas, el declive del Wellfare State, la crisis financiera del 2007-2009, el auge del capitalismo de plataformas hacia 2015 y la pandemia del 2020 parecen indicar que la sociedad capitalista ya no está asentada en una base estable y que las 
crisis cíclicas se desarrollan en ciclos tan cercanos que el concepto mismo de ciclo comienza a percibirse como redundante. En este escenario, los tiempos escolares se tornan insufriblemente eternos y el círculo vicioso de la deslegitimación arranca su andar, contrastando la oferta rígida de esos documentos curriculares con la sabiduría a la carta de la Internet y la asimetría de la relación docente alumno con la interacción aplanada y aluvional de las redes sociales, donde para ser celebrity no hay que esperar acumulando saberes sino seducir y ganar likes aquí y ahora: si la escolaridad necesitaba una inversión de largo plazo, necesitaba sacrificar, necesitaba postergar; la cultura digital marca unos tiempos de preferencia temporal decreciente que provocarían la indignación del viejo Say. Mientras lo escolar suponía proyecto, acumulación y largo plazo, la cultura digital, también lo señalaba Baudrillard, es la del descarte y la realización inmediata: no sé qué es lo que quiero, pero lo quiero ya.

Para colmo, China muestra que es posible una producción capitalista eficiente, híper customizada, con una organización flexible de capital humano infinitamente disponible a precios internacionales ridículos sin que para que los mercados decurrentes de esta organización económica sea necesario la construcción de la ciudadanía liberal de la que la escuela se jactaba ser una operadora monopólica: los derechos humanos, civiles y laborales encarecen los productos y la educación escolar funciona muy bien sin la creatividad, la originalidad y otros valores promovidos por las elites pedagógicas. Todo ello ha sido subsumido en las denominadas "habilidades socioemocionales blandas", que sirven para suavizar el choque con estos tiempos de capitalismo neo-descarnado.

El futuro, pues, ya no es reconocible y si alguna vez lo fue tampoco parece es objeto de conspiraciones. ¿Qué clase de hombre queremos formar?, se preguntaban los personalistas, los educadores freirianos y los pedagogos críticos a pura conspiración edufuturista en tiempos en los que la voluntad racional del pedagogo elucubraba lo posible y alineaba esfuerzos hacia lo imposible. Una pregunta que caducó no solamente porque ese hombre genérico está partido en múltiples pedazos y de hecho una pregunta de ese tipo sería rechazada por sexista, sino porque la utopía del para qué naufraga en el barro de la inmediatez y la imposibilidad de pensar las discontinuidades que nos atraviesan. Y porque si a un pedagogo se le ocurriera formular esa pregunta recibiría, lacónicamente, otra pregunta como respuesta: «¿Desde qué lugar lo está preguntando?», en un intercambio de pliegues y repliegues sin fin.

La cancelación del futuro de lo escolar explica por qué no hay ciencia ficción escolar o, parafraseando a Jameson (2002), por qué se nos es dado imaginar el fin del mundo y no el fin de lo escolar como lo conocemos. Porque, parece, nos es imposible soñar otra cosa por fuera de estos límites, más allá de estos bordes. Ni la ciencia ficción ha logrado transgredir los límites de estas finitudes pedagógicas, suplantando, en casos como en aquellos cuentos de Isaac Assimov (1973), maestros por robots, en forma más bien predecible. 
Sin embargo, Lyotard (2018) fue más allá: la muerte del profesor no viene por el lado fácilmente imaginable de su sustitución por medio de tecnología androide sino por la desaparición de las relaciones sociales asimétricas que parieron al oficio: docentes que se convierten en intermediarios, en meros proveedores de saberes adaptados a la demanda, sin capacidad reflexiva de continuar la alteridad radical propia de lo escolar. En todo caso serán zombis, no robots.

Por otro lado, no solo el futuro sino la aceleración también cuestiona este viejo orden escolar que nos tiene atrapados sin salida como en esas mansiones embrujadas donde las alternativas de fuga siempre abrían puertas que daban a una pared.

Las escuelas eran tecnología que funcionaban en base a combustible adulto híper refinado: uno sujetos educadores que se saben poseedores de conocimiento y portadores de una alteridad radical capaz de proyectar un otro claro y distinto sobre alumnos definidos por su carencia de conocimiento, de valores, de saber vivir; en fin, de su heteronomía. La asimetría fundante de esta relación se define en el escenario de lo que Margaret Mead (2009) llamó cultura posfiguativa; a saber, cambios relativamente estables y lentos que se acumulan progresivamente en quienes más tiempos vivieron; en las generaciones adultas, quienes transmiten ese conjunto da saberes a las nuevas generaciones introduciéndolas en un sistema de signos que incluyen tradiciones de las cuales los adultos, los docentes, son embajadores legítimos y solventes. Como se colige, posfigurativa es la definición de educación del viejo Durkheim - trasmisión de saberes de las generaciones viejas a las generaciones jóvenes- que todos repetimos en piloto automático.

Pero nuestra cultura ha cambiado y ya nadie se legitima por medio de tradiciones; incluso las prosapias más antiguas — sean estas políticas o religiosas- necesitan validarse con giros de época o, al menos, con guiños cómplices a la disrupción. Los cambios son tan constantes y abruptos que el saber acumulado por los mayores corre el riesgo permanente de la obsolescencia en una economía que no produce objetos perdurables cuyos propietarios se jactan de su durabilidad sino mercancías con fechas de vencimiento programadas con corta antelación y cuyos propietarios se jactan, ahora, de su constante sustitución por nuevas y más eficientes prestaciones. Son los procesados en estos cambios - los recién llegados no atados a la tradición; los niños- quienes ostentan la mayor plasticidad para operar en escenarios cambiantes; son ellos los que mantienen la eficacia: una cultura prefigurativa.

Esto no implica que los chicos sepan más que los adultos en el sentido de cantidades de unidades cognitivas, sino que estos deben reconstruir su esquema sapiente y sus valores en forma constante frente a las demandas sociales y son aquellos menos cargados del peso muerto de las tradiciones quienes tendrán más ductilidad para operar satisfactoriamente Como en Moana, la película de Disney (Schurer et al., 2016) si la princesa continuara con la tradición y siguiera sus mandatos, su pueblo quedaría atrapado en su propia extinción. Pero lo de ella no es meramente desobediencia al padre o desafío al poder como se entendería en las 
culturas posfigurativas; de hecho, Moana nunca deja de amar a su papá a quien le extiende una mirada más conmiserativa que desafiante. Se trata de superación: la princesa no transgrede la ley, sino que la reinventa frente a cambios constantes; no rechaza la tradición a la manera de un revolucionario de la modernidad, sino que la reconvierte acelerada y hasta indolentemente, en su opuesto flexible y adaptable.

Esta lógica de aceleración ensucia al combustible adulto propio de lo escolar y acota el espesor de su comburente - las infancias y adolescencias - restringiéndole severamente su accionar, especialmente por las dificultades de configuración de asimetrías en el vértigo de la explosión de saberes consumibles por Internet, de nuevas relaciones aplanadas de las redes sociales y de inteligencia artificial prometiendo customizar los emergentes posibles.

La escuela de la parsimonia y la espera no marida con la cultura prefigurativa propia del capitalismo de aceleración en el sentido de Nick Land (2019a); es decir, un fluir que como acota Sanchiz (2020) es "absoluto", en el sentido que no necesita un sujeto que haga tal o cual cosa; más todavía, ese sujeto también es un epifenómeno de la aceleración. En consecuencia, aquella institución de encierro formadora de cuerpos dóciles que tan bien funcionaba en términos de disciplinamiento se resquebraja, aunque conservando una panoplia de sentidos que la archivan en su rigidez y le permiten propagar memes políticos resaltando su actualidad y prestancia, aunque le nieguen un futuro.

La escolar hace rato dejó de producirse como "cultura caliente», volviendo al texto de Land (2019a); o sea, como lo adaptadora e innovadora que fue en el momento del siglo XVII en el que disolvió el ordenamiento frío de lo escriturado para reciclarlo en una nueva lógica de masas. El texto escolar único surgido en el siglo XVII como parte de la revolución guttenbergiana —desde el Orbis Sensualis Pictus hasta sus choznos del siglo XX - fueron el condimento caliente de la cultura escolar: un instrumento escriturado de abordaje lineal que ligaba con la linealidad y el ritmo de la trayectoria escolar. Por el contrario, en la cultura digital la oferta es hipertextual y con múltiples interfaces que incluyen al mismo libro, pero en formato "electrónico». Es esta cultura caliente, la que tiene capacidad destructiva, invadiendo a las otrora vanguardistas salas de aula graduada y de acceso gratuito para disolver no solo esa linealidad libresca sino también la organizacional: sostener a rajatabla las jerarquías escolares modernas bajo el yugo digital de la organización reticulada precisa de un esfuerzo contracultural destinado a pequeños y aislados éxitos testimoniales, si no al fracaso más rotundo. Un empeño narcisista que, como veremos más adelante, anticipa un destino de frustración.

La potencia escolarizante se enfrió y ya no subvierte nada, aunque produce una sintomatología defensiva para protegerse de los embates calientes de lo digital por medio de retazos de una épica imposible de alardear sino como un canto afónico a lo que fue, a lo que quisiéramos que sea por siempre. Aunque de ella quede una presencia a la que le rendimos homenajes que se niegan a ser póstumos. A la 
que regresamos por medio de subterfugios nostálgicos para corroborar cada día su aspecto fantasmal. Y de la que nos hacemos identitariamente adictos, necesitando de dosis diarias porque, sabemos, la abstinencia nos va a enloquecer o, peor, nos va a hacer cambiar.

Apego extra químico, aunque neurológicamente detectable, que genera reacciones violentas cuando algún distraído osa, en su oscura lucidez, sacudir el ensueño barbitúrico de la escuela poderosa reproduciendo el sonido de las últimas campanadas: son las espectrales patrullas de la pedagogía moderna que - aunque perdidas - son llamativamente numerosas y responden con viscosa y brutal virulencia señalando las herejías y acusando a los herejes. Patrullas que habitan en invernaderos emocionales, en el sentido de Koestler (2016), que aún destartalados y hasta ruinosos conservan el calor que se necesita para seguir honrando la fe en la utopía pedagógica de la modernidad y anatemizando a todo infiel que se interponga en el camino. Patrullas cuya ideología es lo de menos: pueden pertenecer al viejo orden jerárquico y conservador de la derecha o a la izquierda miserable (en el sentido de Land, 2019b) incapaces ambos de dejar de aferrarse al pasado. E pur si muove

Este modo nostálgico supone la tarea constante de subordinar cualquier variante de lo nuevo a la conservación de lo viejo, lo que se expresa en una aproximación técnica, al decir de Jameson (2002). Hace mucho tiempo que la pedagogía solo enarbola la utopía del para qué con el que la modernidad desafiaba a su época y convoca a sus viejos espíritus cuando se siente amenazada, pero ese estado de alerta no es el más frecuente.

En la inerte cotidianeidad posterior a la decimosegunda campanada, la pedagogía abandona toda pretensión de arrogancia histórica y se instala cómodamente en la utopía del cómo, apegándose a las formas del pasado (que siempre son cuestionadas pero nuca discontinuadas) para finalmente lamentar haber optado por estas dosis de practicidad aplanada: si de lo que se trata es de maximizar los resultados, encomiados economistas habrán de ser más cumplidores que los exégetas pedagogos de un pasado que no resucita y allí donde se marchitan en su letargo impotente pudorosas recetas didácticas, florecen funciones de producción educativa prestas a socorrer a quien se pretenda no-improvisado. Batallones muy bien disciplinados de psicometristas todoterreno cantando afinadamente el himno triunfante de los nuevos héroes de recientes victorias de la pura empiría, nuevos salvadores basados en la evidencia. Los sueños pedagógicos en los que la suave melancolía invoca a una técnica entumecida por el paso del tiempo terminan en las peores pesadillas econométricas, las que correlacionan con la cultura caliente del dato.

¿Es esta decimosegunda campanada el postrer llamado al final o acaso hay algo más en su reverberar? Algo, a pesar de todo, quedó abierto: una grieta en la que vivimos incómodamente pero que permite valorar lo más preciado. 


\section{2. ¿A QUiÉn vas a llamar? Cazafantasmas}

La gran artimaña de la pedagogía para contribuir a su propia subsistencia es tomar a la pansofía como rehén de lo escolar; estableciendo que la tecnología es lo que tiene que ser preservado y así convirtiendo, dialécticamente, a los medios en fines. Y tan terca es en su estrategia que prefiere la muerte del rehén antes que rendir la plaza.

En efecto, para Comenius la tecnología escolar era apenas un medio, entre otros, para alcanzar la Pansofía. Como señala Jan Čížek (2019), para Comenius hay enormes posibilidades de que todos alcancen la sabiduría respecto del mundo puesto que la humanidad ahora comparte mucho más conocimiento gracias a la invención de la impresión de libros y gracias a la inundación de nuevas escuelas en las que agricultores y mujeres comunes y corrientes, quienes tenían vedado este acceso, pueden participar del saber que otros humanos generaron. Lo escolar en Comenius es una opción pansofiana o, como lo definía él mismo, un método: un camino posible pero ni único ni eterno.

Frente a esto, la principal virtud de la pedagogía actual para hacer permanecer en el tiempo a la escuela de la modernidad se basa en una obstinación erótica rayana a la compulsión maníaca. En efecto, toda la catexia libidinal está proyectada a un único objeto, la escuela, y esa idealización es la que la torna, como decíamos al comienzo, natural e inherente por sí misma: un desplazamiento que pone todos los atributos positivos en un solo acto e impide negativizarlo como para tomar distancia, para disociarse operativamente del objeto y verlo con otros ojos.

La fascinación por lo escolar es tan fuerte que supone que todas sus dificultades contingentes pueden ser subsanadas en un acto de negación propio de esos amores obsesivos que con tanta declamación babosa y tanta "defensa" de sus defectos no hace más que esconder el carácter compulsivamente narcisista de la proyección. Salir en defensa de la escuela es salir en defensa de un objeto, no de un deseo; es convocar a los fantasmas del pasado glorioso para preservar un presente inquietante. Salir en defensa de la escuela es, sencillamente, salir en nuestra propia defensa, aunque el relato pedagógico se nutra de una estética bondadosa y altruista mientras nadie se ocupa de la pansofía, la principal damnificada

Como a todo gran narcisista, la frustración no le hace mella y la realidad es la culpable de los problemas por no adaptarse a la teoría. Por eso, se suceden esos acting sobre reaccionados frente a quienes señalan la endeblez de su yo idealizado. Cuanto más frágil, más idealizado y por tanto mayor la sobre reacción frente a la frustración. El perfil ególatra de la pedagogía, con su tendencia a introyectar dentro de la escuela todo lo bueno y proyectar fuera todo lo malo acaba por trastornar su sentido de realidad y con el eco sordo de un coro de aullantes infinitivos, consigue un transitorio triunfo pírrico en la que se perpetúa al ver desfallecer aquello que le dio sentido primal. Y, al igual que Narciso, la pedagogía también se está ahogando al extasiarse con su propio reflejo, aunque su rostro neurótico se maquille de un 
voluntarismo mágico que su omnipotencia narcisista guía a callejones sin salida y sin GPS capaz de recalcular.

Con Fisher (2018) podemos concluir que fracasos y frustraciones que no podemos ocultarnos se transforman en un vector funcional al realismo capitalista: la herida narcisista cuando rebalsa a la iracundia se transforma en depresión y en ella vivimos nuestra resultante terminal, nuestro síntoma socialmente requerido: cuando el barullo multiforme se ensordece, cuando las rabietas se calman, cuando los acusaciones resultan intrascendentes, es ahí donde nos vemos como los únicos responsables de nuestra miseria y, por ende, como sus dignos merecedores.

Ser un cazafantasmas de lo escolar supone la tarea de identificar esos núcleos eróticos motorizados por la pulsión narcisista y ponerlos en valor, liberándolos del secuestro por medio de la apología irreflexiva de lo escolar. Aunque no nostálgica —a la sazón antinostálgica - esta operación también es histórica, con una columna vertebral estirada más hacia adelante que hacia atrás, o tomando a Galliano (2018),

hay bolsones de futurismo en el pasado que pueden ser explotados para pensar presentes alternativos sin necesidad de nostalgia ni alienación (...se trata de) activar esos bolsones de futurismo pasado no como nostalgia, sino como una carencia, un ruido incómodo que puede tener un efecto subversivo en la cerrazón política presente.

Esa carencia es el rehén. Lo escolar surgió en el siglo XVII como una tecnología para reunificar lo que la escritura había separado y consolidar una sociedad en la que todo el saber humano sea para todos los seres humanos. Esta visión entre enciclopedista y neo-estoica que —en la lectura de Hamilton (1992)— calzó con el proyecto moderno, pero este no consiguió realizarlo. La potencia de lo pansofiano supera por mucho el ideal ilustrado y permite entender formas convivenciales de relación social, tal como lo explicara muy bien Ivan Illich (Narodowski, 2017). Lo escolar, entonces, no era un fin en sí mismo si no apenas una herramienta para la pansofía... es imprescindible entender que la lógica depresiva de exaltación de lo escolar por la vía de la exhumación de sus cadáveres refuerza la imposibilidad que el capitalismo real impone a la pansofía.

Un exorcismo bien practicado podrá extraer de lo escolar los demonios más atractivos, sabiendo que en esa admonición probablemente la escuela agonice de la mejor manera posible: portando su nombre con dignidad, aunque, como la nave Argos, con elementos constituyentes completamente diferentes a los originales. La escuela que conocimos incluyó los infinitos cognoscibles de la modernidad. Ahora desbordada, nuevos infinitos buscan que pase a una mejor vida para que, pansofianamente, se puedan incluir. Esta mirada, por tanto, no es "pesimista" solo por no inscribirse en la nostalgia por la escuela que no fue para así desdoblarse de modo obstinado en una retahíla de sentidos autoindulgentes. Si bien resulta sin dudas escéptica, se posiciona pretendiendo liberar al ideal pansófico de la sujeción a un único formato educativo y, por tanto, proponiendo un horizonte frente a la crisis actual. 
Con esta maniobra más lejana del dolor y la vergüenza compasiva que de una desafiante eutanasia proactiva, podremos escoger dispositivos de lo escolar sin embadurnarnos con su gramática. Podremos dejarnos seducir por el ruido incómodo de su desajuste y entregarnos al frenesí de lo desconocido. Podremos profanar sus rituales sin temor al castigo. Podremos intervenir sus rutinas, mezclarlas, tunearlas, aleatorizarlas. Podremos intrusar sus espacios simbólicos y también los físicos, okuparlos, desintoxicarlos de burocracias. Podremos hackearla, aunque el verbo sea remanido: interferir los sistemas y tomar control de algunos de sus clústeres. Podremos catarla, cirujearla, cartonearla. Podremos destumorizarla o, en el peor de los casos, hacerla asintomática. Podremos, enteros o a pedazos, sostener este pseudoprograma contra el neodisplinamiento de las corporaciones y la pretensión re-modernizadora del transhumanista. ¿Podremos?

Podremos usar algunos de sus módulos, así como muchos otros propios de la cultura digital en un proceso schumpeteriano de destrucción creativa que el capitalismo neo descarnado le viene negando a lo escolar hace tiempo, obligándonos a vivir de sus recuerdos, sus fantasmas, las sobras de su añejo banquete.

El objeto libidinal a catextizar, el deseo, no es el recurso sino la finalidad: aquellas son cambiantes, contingentes, a la carta... son objetos; estas son estratégicas y se corresponden con lo que podemos amar. No es recomendable el fetichismo, ni siquiera por la escuela ni por sus fantasmas, así como, contrariando a Roger Taylor (Queen, 1975), no es conveniente enamorarte de tu auto.

\section{REFERENCIAS BIBLIOGRÁFICAS}

Asimov, I., \& Lazar, D. (1973). The Best of Isaac Asimov. Sphere Books.

Baudrillard, J., \& Brühmann, H. (1977). Oublier Foucault. Éditions Galilée.

Butler, O. (1989). Xenogénesis-I Dawn. Ultramar Editores.

Č́žzek, J. (2019). From Pansophia to Panorthosia: The Evolution of Comenius's Pansophic Conception. Erudition and the Republic of Letters, 4(2). https://doi.org/10.1163/2405506900402002

Comenius, J. A. (1986). Didáctica magna. Ediciones Akal.

Fisher, M. (2018). Los fantasmas de mi vida. Escritos sobre depresión, hauntología y futuros perdidos. Caja Negra.

Galliano, A. (2018). ¿Para qué nos sirve Mark Fisher? Caja Negra. https://cajanegraeditora. com.ar/blog/para-que-nos-sirve-mark-fisher/

Hamilton, D. (1992). Comenius and the new world order. Comenius, 46, 157-171.

Jameson, F. (2002). Posmodernismo y sociedad de consumo. En H. Foster, La posmodernidad (pp. 9-28). Kairós.

Koestler, A. (2016). En busca de la utopía. Memorias, novelas y ensayos políticos, seleccionados y comentados por el autor. Kairós.

Land, N. (2019a). Colapso. En A. Avanessian \& M. Reis (Comps.), Aceleracionismo. Estrategias para una transición al postcapitalismo (pp. 13-32). Caja Negra. 
Land, N. (2019b). Crítica del miserabilismo trascendental. En A. Avanessian \& M. Reis (Comps.), Aceleracionismo. Estrategias para una transición al postcapitalismo (pp. 51-62). Caja Negra.

Lyotard, J. F. (2018). La condition postmoderne: rapport sur le savoir. Minuit.

Mead, M. (2009). Cultura y compromiso. El lenguaje de las nuevas generaciones. Gedisa.

Narodowski, M. (1994). Infancia y poder. La conformación de la pedagogía moderna. Aique.

Narodowski, M. (2017). Looking for Asymmetries: A theoretical approach to the feeling of nostalgia regarding childhood in a pre-figurative culture. En L. Wesseling, Lies (Ed.), Reinventing Childhood Nostalgia. Books, Toys and Contemporary Media Culture (pp. 107-120). Routledge.

Queen. (1975). I'm in love with my car. En, A night at the opera [CD]. EMI.

Querrien, A. (2005). L'école mutuelle: une pédagogie trop efficace? Seuil.

Sanchiz, R. (2020). Desplazamientos del futuro. Cuaderno de Afuera, Blog. https://alafuera. art.blog/2020/09/01/cuaderno-de-afuera-desplazamientos-del-futuro-por-ramiro-sanchiz/

Say, J. B. (1861). Traité d'économie politique. Calmann-Lévy.

Shurer, O. (productora) y Clements. R. y Musker, J. (directores). (2016). Moana [cinta cinematográfica]. Walt Disney Pictures-Walt Disney Animation Studios. 